Saudi Journal of Medical and Pharmaceutical Sciences

Abbreviated Key Title: Saudi J Med Pharm Sci

ISSN 2413-4929 (Print) |ISSN 2413-4910 (Online)

Scholars Middle East Publishers, Dubai, United Arab Emirates

Journal homepage: https://saudijournals.com

Original Research Article

\title{
Prevalence of Heavy Menstrual Bleeding in Women Taking Rivaroxaban
}

Dr. Salhah Saleh Alsulami ${ }^{1 *}$, Dr. Abdulaziz Alrashed ${ }^{2}$, Ms. Ghada Alammar ${ }^{3}$, Ms. Rehab Almubrick ${ }^{3}$, Ms. Malak Alotaibi $^{3}$, Ms. Deemah Al-Saud ${ }^{3}$, Ms. Dana Aleissa ${ }^{3}$, Dr. Osama Alsayed ${ }^{4}$

${ }^{1}$ Assistant Professor at King Abdulaziz University-Rabigh College of Medicine, Women's Health Fellow, King Faisal Specialist Hospital and Research Center, Makkah Al Mukarramah Branch Rd, Al Mathar Ash Shamali, Riyadh 11564, Saudi Arabia

${ }^{2}$ Consultant, Department of Medicine, King Faisal Specialist Hospital and Research Center, Makkah Al Mukarramah Branch Rd, Al Mathar Ash Shamali, Riyadh 11564, Saudi Arabia

${ }^{3}$ Bio-Statistics, Epidemiology and Scientific Computing Department, King Faisal Specialist Hospital and Research Center, Makkah Al Mukarramah Branch Rd, Al Mathar Ash Shamali, Riyadh 11564, Saudi Arabia

${ }^{4}$ Resident, Department of Medicine, King Faisal Specialist Hospital and Research Center, Makkah Al Mukarramah Branch Rd, Al Mathar Ash Shamali, Riyadh 11564, Saudi Arabia

DOI: $10.36348 /$ sjmps.2021.v07i02.005 $\quad$ | Received: 30.01 .2021 | Accepted: 16.02.2021 | Published: 17.02 .2021

*Corresponding author: Salhah Saleh Alsulami

\section{Abstract}

Background: Bleeding is a common side effect during anticoagulant therapy. Rivaroxaban, a new anticoagulant, presents concerns regarding its association with heavy menstrual bleeding. Objectives: Our aim is to measure the prevalence of heavy menstrual bleeding in women taking rivaroxaban. We aim to measure the median Pictorial Blood Assessment Chart (PBAC) score, and its association with iron deficiency anemia (IDA), passage of clots, and age, respectively. Methods: This was a prospective, non- interventional study set in a thrombosis clinic. There were 49 patients enrolled. The study consisted of two parts: a retrospective part regarding collection of menstrual history data before starting rivaroxaban; and a prospective part using validate Arabic PBAC for the next three menstrual cycles. Main outcome measures: Prevalence of heavy menstrual bleeding among women taking rivaroxaban. Results: The median PBAC score for women taking rivaroxaban for an average of 3 months was 211, IQR $(42.5,375.9)$ The prevalence of heavy menstrual bleeding in women taking rivaroxaban was $22 \%$. There is a weak correlation between IDA and age, and IDA and average PBAC score. Conclusion: Rivaroxaban may cause heavy menstrual bleeding, but it does not lead to prolongation of menstruation. A detailed menstrual history should be taken before considering rivaroxaban for women in reproductive age.

Keywords: Heavy menstrual bleeding, rivaroxaban, anticoagulation, deep vein thrombosis, pulmonary embolism.

Copyright $\odot 2021$ The Author(s): This is an open-access article distributed under the terms of the Creative Commons Attribution 4.0 International License (CC BY-NC 4.0) which permits unrestricted use, distribution, and reproduction in any medium for non-commercial use provided the original author and source are credited.

\section{BACKGROUND}

Venous thromboembolism (VTE) is a common disease, and deep vein thrombosis (DVT) and pulmonary embolism (PE) are the two most common forms of VTE. It affects 1-10 per 10,000 women of reproductive age $[1,2]$. Anticoagulation is the main stay of treatment, and prolonged treatment is required for at least 3 months [3]. Bleeding is a major concern for anticoagulants. The use of direct oral anticoagulants (DOACs) is increasing for the treatment of VTE and non-valvular atrial fibrillation. Rivaroxaban showed comparable safety and efficacy to vitamin $\mathrm{K}$ antagonists (VKA) on EINSTEIN-DVT and PE studies [4, 5]. Female gender has been associated with a higher risk of major and clinically relevant non-major bleeding when prescribed anticoagulants, including DOACs [6]. A type of non-major bleeding is heavy menstrual bleeding
(HMB), affecting 10-30\% of women during some point of their child-bearing years in the absence of anticoagulation therapy [7, 8]. The use of rivaroxaban was associated with prolongation of menstrual bleeding, and an increased need for medical or surgical intervention. In addition, one study [9] suggested that its use required adaptation of anticoagulant treatment due to abnormal uterine bleeding (AUB), as compared to VKAs. In another study, $20 \%$ of 128 patients using rivaroxaban reported heavy menstrual bleeding [10], and another study found that $25 \%$ of women on rivaroxaban complained of heavy menstrual bleeding [11].

The Pictorial Blood Assessment Chart (PBAC) was initially designed to quantify menstrual blood loss. A score of 100 or more, used to diagnose menorrhagia, found sensitivity and specificity of more than $80 \%$ of 
those evaluated [12]. In Saudi Arabia, there is no specific data regarding the effect of rivaroxaban on menstrual bleeding.

\section{OBJECTIVES \\ Primary Objectives}

To evaluate the prevalence of heavy menstrual bleeding among women using rivaroxaban.

\section{Secondary Objectives}

To evaluate the:

Median score of PBAC on women taking rivaroxaban. Median duration of menstruation, percentage of clots, iron deficiency anemia (IDA), and intermenstrual and post-coital bleeding before and after anticoagulation. Correlation between PBAC score and age, IDA.

Design: Observational prospective study

Setting: Thrombosis clinic

\section{Material ANd Methods}

After obtaining scientific and ethical approval from office of research affairs we started our study. First, we followed the guidelines of Tsang [13] in developing, translating, and validating the PBAC to the Arabic language. Then, we tested our proposed Arabic PBAC on 25 women not undergoing anticoagulant therapy.

After that we started the study by screening 57 patients over a period from January until October 2018; 49 patients met the inclusion criteria.

\section{Inclusion criteria}

We included Saudi women aged from 14 to 55 years who were not menopausal, and who had been administered rivaroxaban for the last one month for deep vein thrombosis (DVT), pulmonary embolism (PE), or atrial fibrillation.

\section{Exclusion Criteria}

We excluded women who had undergone hysterectomy, and women who had been diagnosed with any bleeding disorder, including Von Willebrand disease.

After obtaining verbal consent, we directed up close and personal meetings with patients in the thrombosis clinic. We obtained information about age, marital status, use of contraception, and the length and planned duration of anticoagulation therapy. We also obtained information about their menstrual history before beginning anticoagulation. This information included duration, passage of clots, intermenstrual postcoital bleeding, and diagnosis of IDA. Any changes related to these factors were evaluated from that point onward to decide if it was necessary to change to another anticoagulant, or to alter the administration of rivaroxaban; specifically, to discontinue the administration of the drug for more than two days. In addition, we evaluated if it was necessary to consult a gynecologist for their heavy periods. At that point, we requested that they fill in the Arabic PBAC (disclosed by a member of the research team) with their next three menstrual cycles. We gave each patient standardized sanitary pads. We sent updates by instant message, and telephone calls with the patients helped to guarantee adherence to recording menstrual bleeding.

During follow-up, 8 out of 49 patients did not return the charts. When we reached out to them to find out why, we found that five of them had achieved menopause during the study period; one had amenorrhea secondary to hormonal intrauterine contraceptive device (IUCD) insertion; and one had changed their anticoagulant medication to enoxaparin. In addition, we lost contact with one patient.

\section{Primary Outcome Measures \\ Primary Outcome}

The prevalence of heavy menstrual bleeding among women using rivaroxaban.

\section{Secondary Outcome}

The median of duration of menstruation, passage of clots, and diagnosis with IDA before and after the use of rivaroxaban.

IDA.

The correlation between PBAC score and age,

\section{RESUlTS}

49 patients were enrolled in the study and gave verbal consent. Baseline characteristics are shown in Table-1.

As from our pilot study on women not undergoing anticoagulant therapy, the median PBAC score was 72 IQR $(37.5,158.5)$, and $95^{\text {th }}$ centile was 339. We defined heavy menstrual bleeding as any score above 339 . The prevalence of heavy menstrual bleeding among women taking rivaroxaban is $22 \%$. The median PBAC score for an average of 3 months was 211, IQR (42.5, 375.9). The menstrual history before and after starting rivaroxaban is shown in Table-2.

On multivariate correlations, we found a weak positive correlation between age and average PBAC score, as shown in Figure 1 and 2.

In using Spearman's correlation coefficient, there is a weak correlation between IDA and age, and IDA and average PBAC score, as shown in Figure-3. 
Salhah Saleh Alsulami et al., Saudi J Med Pharm Sci, Feb, 2021; 7(2): 102-106

Table-1: Baseline characteristics of patients

\begin{tabular}{|l|l|}
\hline Median age & $\mathbf{3 8}$ years IQR (30,43.5) \\
\hline Marital status & $(35,72 \%)$ married \\
& $(10,20 \%)$ single \\
& $(4,8.2 \%)$ divorced/widow \\
\hline Indication of anticoagulation & $(16,32.7 \%)$ DVT \\
& $(11,22.4 \%)$ PE \\
& $(6,12.2 \%)$ DVT and PE \\
& $(2,4.1 \%)$ Non-valvular AF \\
\hline Duration of anticoagulation & $(8,16.3 \%) 1$ month \\
& $(3,6.1 \%) 2$ months \\
& $(5,10.2 \%) 3$ months \\
\hline Intended duration of anticoagulation & More than 3 months (33, 67.3\%) \\
\hline Contraception & $(2,4.2 \%) 3$ months \\
& $(3,6.3 \%) 6$ months \\
\hline Percentage of women needed to alter anticoagulation (discontinue for 2 or more days) & $(7,14.6 \%) 1$ year \\
\hline Percentage of women needed to switch anticoagulation & $(36,75 \%)$ lifelong \\
\hline Percentage of women needed to consult gynecologist for heavy periods & $94 \%$ Not using any contraception \\
\hline
\end{tabular}

Table-2: Menstrual history before and after starting rivaroxaban

\begin{tabular}{|l|l|l|}
\hline & Before starting rivaroxaban & After starting rivaroxaban \\
\hline Median duration of menstruation & 7 days IQR $(5.5,7)$ & 7 days IQR $(6.5,9)$ \\
\hline Percentage of women passing clots & $21(42.9 \%)$ & $29(59.2 \%)$ \\
\hline Diagnosis of IDA & $31(63.3 \%)$ & $27(55.1 \%)$ \\
\hline Intermenstrual bleeding & $1(2 \%)$ & $7(14.3 \%)$ \\
\hline Post-coital bleeding & $2(5.1 \%)$ & $2(5.1 \%)$ \\
\hline
\end{tabular}

Figure: 1

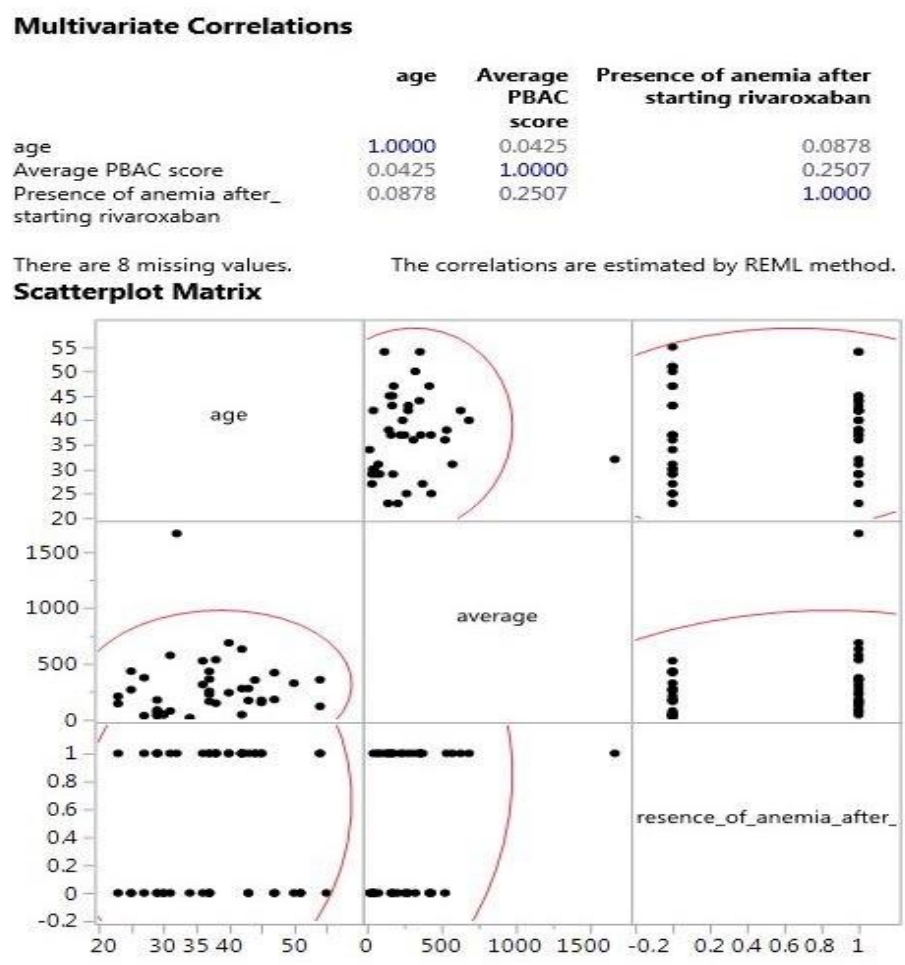



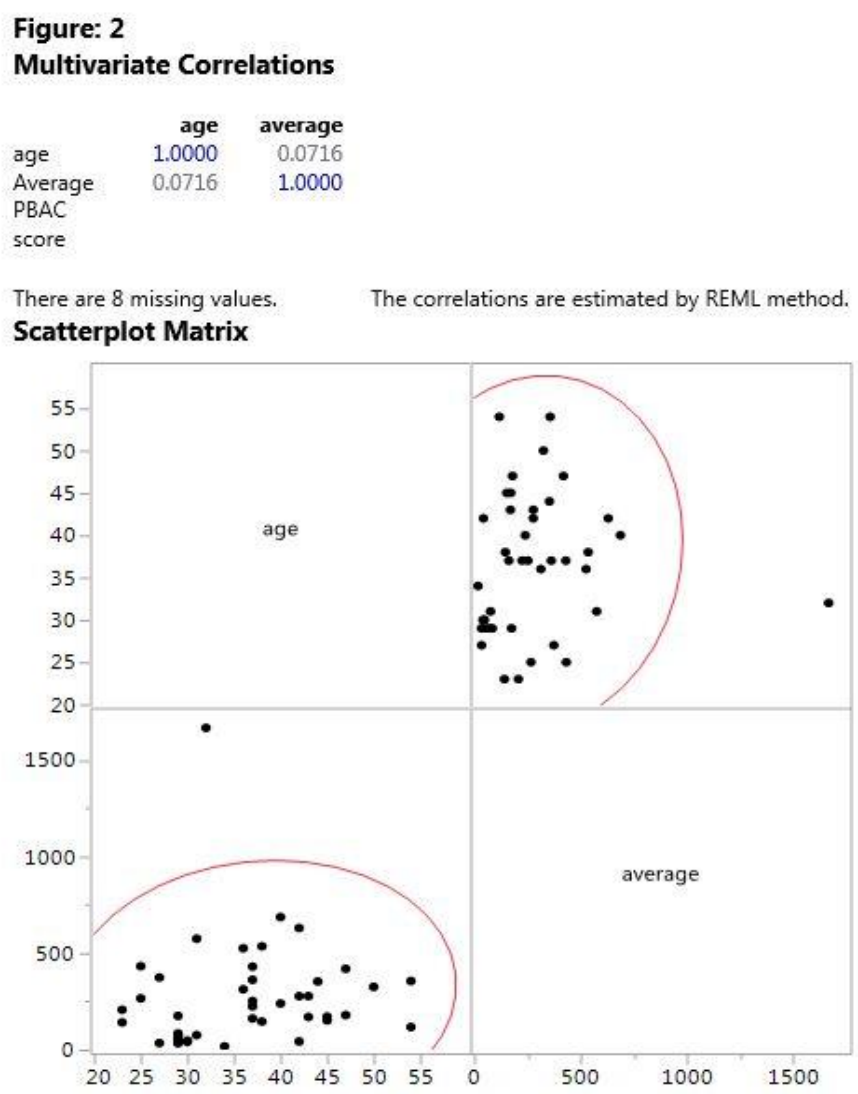

Figure: 3

Nonparametric: Spearman's $\rho$

\begin{tabular}{llrr|r|} 
Variable & by Variable & Spearman $\rho$ & Prob $>|\rho|$ \\
Average PBAC core & age & 0.2354 & 0.1384 \\
$\begin{array}{l}\text { Presence of anemia after_ } \\
\text { starting rivaroxaban }\end{array}$ & age & 0.1047 & $0.4742 \mid$ \\
$\begin{array}{l}\text { Presence of anemia after } \\
\text { starting rivaroxaban }\end{array}$ & $\begin{array}{l}\text { Average } \\
\text { PBAC score }\end{array}$ & 0.2398 & $0.1311 \mid$
\end{tabular}

\section{LIMITATIONS}

This is a prospective study, and therefore has various limitations. First, the number of patients selected was small. Second, not all patients returned the charts. Third, the history of menstrual cycle prior to initiation of rivaroxaban can be affected by recall bias. Fourth, a 3-month follow-up is too short of time to decide on the percentage of women who may need to switch to another anticoagulant. Finally, IDA was diagnosed less in women taking rivaroxaban, which may be explained by early diagnosis and treatment of IDA. These patients are on a routine follow-up for complete blood count with each clinic visit.

\section{Conclusions}

Rivaroxaban was associated with heavy menstrual bleeding in previous studies. In our prospective study, we found rivaroxaban was associated with a high prevalence of heavy menstrual bleeding, but not prolongation of menstruation. It is associated with an increase in intermenstrual bleeding and passage of clots. It also increases the need for anticoagulation therapy, and the need to consult a gynecologist for heavy periods. We recommend a detailed menstrual history for any women in reproductive age who require anticoagulation, and who report heavy periods to avoid rivaroxaban. We also recommend that the follow-up should include a complete blood count to evaluate for the presence of IDA. Another study with larger number of patients is required. 


\section{Conflict of interest: None}

\section{REFERENCES}

1. Heinemann, L. A., \& Dinger, J. C. (2007). Range of published estimates of venous thromboembolism incidence in young women. Contraception, 75(5), 328-336.

2. Vandenbroucke, J. P., Rosing, J., Bloemenkamp, K. W., Middeldorp, S., Helmerhorst, F. M., Bouma, B. N., \& Rosendaal, F. R. (2001). Oral contraceptives and the risk of venous thrombosis. New England Journal of Medicine, 344(20), 1527-1535. Available from: http://www.nejm.org/doi/abs/10.1056/NEJM2001 05173442007

3. Wells, P. S., Forgie, M. A., \& Rodger, M. A. (2014). Treatment of venous thromboembolism. Jama, 311(7), 717-728. Available from:

http://www.ncbi.nlm.nih.gov/pubmed/24549552\% 5Cnhttp://jama.jamanetwork.com/article.aspx?doi $=10.1001 /$ jama. 2014.65

4. Einstein Investigators. (2010). Oral rivaroxaban for symptomatic venous thromboembolism. New England Journal of Medicine, 363(26), 24992510. Available from: http://www.nejm.org/doi/full/10.1056/NEJMoa10 07903

5. Prins, M. H., Lensing, A. W., Bauersachs, R., Van Bellen, B., Bounameaux, H., Brighton, T. A., ... \& Wells, P. S. (2013). Oral rivaroxaban versus standard therapy for the treatment of symptomatic venous thromboembolism: a pooled analysis of the EINSTEIN-DVT and PE randomized studies. Thrombosis journal, 11(1), 1-10. Available from: http://www.ncbi.nlm.nih.gov/pubmed/24053656\% 5Cnhttp://www.pubmedcentral.nih.gov/articlerend er.fcgi? artid $=3850944 \&$ tool $=$ pmcentrez\&renderty pe=abstract

6. Alotaibi, G. S., Almodaimegh, H., McMurtry, M. S., \& Wu, C. (2013). Do women bleed more than men when prescribed novel oral anticoagulants for venous thromboembolism? A sex-based metaanalysis. Thrombosis research, 132(2), 185-189. Available from:

http://dx.doi.org/10.1016/j.thromres.2013.07.017

7. Lethaby, A., \& Farquhar, C. (2003). Treatments for heavy menstrual bleeding. BMJ, 327: 12431244. Available from: http://www.ncbi.nlm.nih.gov/pubmed/14644939\% 5Cnhttp://www.pubmedcentral.nih.gov/articlerend er.fcgi?artid=PMC286237

8. Liu, Z., Doan, Q. V., Blumenthal, P., \& Dubois, R. W. (2007). A systematic review evaluating health- related quality of life, work impairment, and health- care costs and utilization in abnormal uterine bleeding. Value in health, 10(3), 183-194.

9. De Crem, N., Peerlinck, K., Vanassche, T., Vanheule, K., Debaveye, B., Middeldorp, S., ... \& Peetermans, M. (2015). Abnormal uterine bleeding in VTE patients treated with rivaroxaban compared to vitamin $\mathrm{K}$ antagonists. Thrombosis research, 136(4), 749-753.

10. Ferreira, M., Barsam, S., Patel, J. P., Czuprynska, J., Roberts, L. N., Patel, R. K., \& Arya, R. (2016). Heavy menstrual bleeding on rivaroxaban. British journal of haematology, 173(2), 314-315.

11. Myers, B., \& Webster, A. (2017). Heavy menstrual bleeding on Rivaroxaban- Comparison with Apixaban. British journal of haematology, 176(5), 833-835.

12. Higham, J. M., O'brien, P. M. S., \& Shaw, R. (1990). Assessment of menstrual blood loss using a pictorial chart. BJOG: An International Journal of Obstetrics \& Gynaecology, 97(8), 734-739.

13. Tsang, S., Royse, C. F., \& Terkawi, A. S. (2017). Guidelines for developing, translating, and validating a questionnaire in perioperative and pain medicine. Saudi journal of anaesthesia, 11(Suppl 1), S80. Available from: http://www.saudija.org/text.asp?2017/11/5/80/207 056 